\title{
Degradação ruminal e digestibilidade intestinal da proteína bruta de alimentos para bovinos ${ }^{1}$
}

\author{
Marcos Inácio Marcondes ${ }^{2}$, Sebastião de Campos Valadares Filho ${ }^{3}$, Edenio Detmann ${ }^{3}$, Rilene \\ Ferreira Diniz Valadares ${ }^{3}$, Luiz Fernando Costa e Silva ${ }^{3}$, Mozart Alves Fonseca ${ }^{3}$ \\ ${ }^{1}$ Pesquisa financiada pela Fundação de Amparo à Pesquisa de Minas Gerais (FAPEMIG)/Centro Nacional de Pesquisa (CNPq)/Pronex. \\ 2 Doutorando, DZO-UFV, Viçosa-MG, CEP:36570-000. \\ 3 Universidade Federal de Viçosa, Viçosa-MG, CEP:36570-000.
}

RESUMO - Este trabalho foi conduzido com os objetivos de determinar as frações A e B e a taxa de degradação ruminal (Kd) da matéria seca (MS) e da proteína bruta (PB) de 27 alimentos e avaliar a digestibilidade intestinal da proteína nãodegradada no rúmen pelas técnicas do saco de náilon móvel e de três estágios. Os alimentos avaliados foram farelos de arroz, babaçu, gérmen de milho e trigo; milho desintegrado com palha e sabugo, milho desintegrado com sabugo, milho, polpa cítrica, sorgo, amireia, farelos de algodão com 28, 38 e 46\% de PB, farelos de amendoim, girassol e soja; feijão-bandinha, glúten de milho, grão de soja, levedura, promil, refinazil, cascas de cacau, café e soja e silagens de capim-elefante e milho. Para obtenção da degradabilidade ruminal da MS e PB dos alimentos, utilizaram-se sacos de náilon de $10 \times 20 \mathrm{~cm}$ e os tempos de incubação de $0,2,4,6,12,16,24,48$ e 72 horas. A digestibilidade intestinal foi determinada pelas técnicas do saco de náilon móvel e de três estágios. Os dados de degradação ruminal da matéria seca e da proteína bruta, em sua maioria, estão de acordo com a literatura. A técnica dos três estágios não estimou de forma satisfatória a digestibilidade interstinal de todos os alimentos estudados em conjunto, mas foi adequada para os alimentos proteicos. A maioria dos alimentos possui aproximadamente $90 \%$ de digestibilidade da PB, com exceção das cascas de soja, café e cacau e das silagens de milho e capimelefante. A técnica de três estágios estimou corretamente a digestibilidade intestinal dos alimentos proteicos, mas recomenda-se a utilização da equação DIPB $(\%)=-5,1906+1,1053 \times \mathrm{X}$ para corrigir a digestibilidade obtida pela técnica dos três estágios para alimentos não-proteicos.

Palavras-chave: babaçu, feijão, promil, saco de náilon móvel, subprodutos da indústria, três estágios

\section{Rumen degradation and intestinal digestibility of crude protein in feeds for cattle}

\begin{abstract}
The objective of the present study was to determine the A and B fractions and the rumen degradation rate $(\mathrm{Kd})$ of dry matter (DM) and crude protein (CP) in 27 feeds and determine the intestinal digestibility of non-degraded rumen protein by the three steps and mobile nylon bag techniques. Rice meal, babassu meal, wheat and corn germ, ground corn cobs and straw, ground corn cobs, corn, citrus pulp, sorghum, starea and cottonseed meal with 28,38 and $46 \% \mathrm{CP}$, peanut meal, sunflower meal, soybean meal, bean byproduct, corn gluten, soybean grain, dry yeast, corn gluten meal, cacao hulls, coffee hulls, soybean hulls, elephant-grass silage and corn silage were sampled. To obtain the ruminal degradation of DM and CP, $10 \times 20 \mathrm{~cm}$ nylon bags with incubation times of $0,2,4,6,12,16,24,48$ and 72 hours were used. The intestinal digestibility was determined by the three steps and the mobile nylon bag techniques. The ruminal degradation data of the dry matter and crude protein were similar to the literature. The three step technique did not estimate properly the intestinal digestibility of all the feeds evaluated, excepted for the protein feeds. Most feeds had total CP digestibility close to $90 \%$, excepted for soybean, coffee and cacao hulls and elephant-grass and corn silage. The three step technique correctly estimated the intestinal digestibility of the protein feeds, but the equation IDCP $(\%)=-5,1906+1,1053 \times \mathrm{X}$ is recommended to correct the digestibility obtained by the three steps technique for non-protein feeds.
\end{abstract}

Key Words: babassu, bean, industry byproducts, mobile nylon bag, promil, three steps

\section{Introdução}

A degradação ruminal da proteína bruta $(\mathrm{PB})$ da dieta influencia tanto a fermentação ruminal como o suprimento de aminoácidos no intestino delgado. O conhecimento da dinâmica de degradação ruminal da proteína dos alimentos é fundamental para a formulação de dietas com adequadas quantidades de proteína degradável no rúmen (PDR) para 
os microrganismos do rúmen e proteína não-degradável no rúmen (PNDR) para o próprio animal (NRC, 2001), resultando em dietas mais eficientes. Além da degradação ruminal, a obtenção do valor proteico do alimento expresso como aminoácidos verdadeiramente digestíveis no intestino tem sido abordada nos novos sistemas de avaliação proteica dos alimentos e envolve a mensuração de diversas características (Madsen et al., 1995). Para quantificar a contribuição dos aminoácidos absorvidos no intestino delgado, é necessário o desenvolvimento de métodos simples e econômicos para estimativa da digestibilidade intestinal dos alimentos (Hvelplund \& Weisbjerg, 2000).

Assim, realizou-se este trabalho para determinar as frações $\mathrm{A}$ e B e a taxa de degradação ruminal $(\mathrm{Kd})$ da matéria seca e da proteína bruta de 27 alimentos utilizados na alimentação de bovinos e avaliar a digestibilidade intestinal da proteína não-degradada no rúmen pela técnica do saco de náilon móvel e pela técnica de três estágios.

\section{Material e Métodos}

O experimento foi realizado no Laboratório de Animais do Departamento de Zootecnia da Universidade Federal de Viçosa (UFV), em Viçosa, Minas Gerais, com a fase de campo realizada em outubro de 2004.

Os alimentos avaliados foram: farelo de arroz, farelo de babaçu, gérmen de milho e farelo de trigo; milho desintegrado com palha e sabugo (MDPS); milho desintegrado com sabugo (MDS); milho moído; polpa cítrica; sorgo moído; amireia; farelos de algodão com 28 , 38 ou $46 \%$ de PB; farelos de amendoim, girassol e de soja; feijão-bandinha; glúten de milho; grão de soja; levedura; promil; refinazil; cascas de cacau, café e de soja; e silagens de capim-elefante e de milho. Todas as amostras de alimentos foram primeiramente trituradas em moinhos de facas com poros de $1 \mathrm{e} 2 \mathrm{~mm}$ e analisadas para determinação de sua composição nutricional (Tabela 1).

Tabela 1 - Composição química dos alimentos avaliados

\begin{tabular}{|c|c|c|c|c|c|c|c|c|c|c|c|c|}
\hline Amostra & $\begin{array}{c}\text { Matéria }^{1} \\
\text { seca }\end{array}$ & $\begin{array}{c}\text { Proteína } \\
\text { bruta }^{2}\end{array}$ & $\begin{array}{l}\text { Extrato } \\
\text { etéreo }^{2}\end{array}$ & $\begin{array}{c}\text { Fibra em } \\
\text { detergente } \\
\text { neutro } \\
(\mathrm{FDN})^{2}\end{array}$ & $\begin{array}{l}\text { Fibra em } \\
\text { detergente } \\
\text { ácido } \\
(\text { FDA })^{2}\end{array}$ & $\mathrm{FDNcp}^{2}$ & FDAcp $^{2}$ & Cinzas $^{2}$ & $\begin{array}{c}\text { Carboidratos } \\
\text { não- } \\
\text { fibrosos }^{2}\end{array}$ & $\mathrm{CNFcp}^{2}$ & $\begin{array}{c}\text { PIDN/ } \\
\mathrm{PB}^{3}\end{array}$ & $\begin{array}{c}\text { PIDA } \\
/ \mathrm{PB}^{3}\end{array}$ \\
\hline \multicolumn{13}{|l|}{ Alimento energético } \\
\hline Farelo de arroz & 89,29 & 15,71 & 2,43 & 22,76 & 9,06 & 20,03 & 8,28 & 14,61 & 44,49 & 47,23 & 13,26 & 3,16 \\
\hline Farelo de babaçu & 95,17 & 16,99 & 0,24 & 38,46 & 25,01 & 32,30 & 23,12 & 4,13 & 40,18 & 46,35 & 35,10 & 7,04 \\
\hline Farelo de trigo & 89,44 & 17,15 & 0,90 & 24,42 & 6,38 & 20,99 & 6,08 & 3,99 & 53,55 & 56,97 & 18,28 & 1,64 \\
\hline Farelo de gérmen de milho & 97,34 & 10,33 & 7,73 & 11,73 & 2,38 & 10,27 & 2,26 & 6,62 & 63,59 & 65,04 & 7,87 & 1,05 \\
\hline MDS & 90,16 & 7,23 & 1,12 & 21,73 & 3,13 & 20,18 & 3,04 & 1,65 & 68,27 & 69,82 & 13,97 & 1,16 \\
\hline MDPS & 89,83 & 6,59 & 1,14 & 19,86 & 6,87 & 18,70 & 6,69 & 1,89 & 70,52 & 71,68 & 11,72 & 1,53 \\
\hline Milho & 89,52 & 8,94 & 0,77 & 10,49 & 1,51 & 9,78 & 1,45 & 1,61 & 78,18 & 78,89 & 6,04 & 0,45 \\
\hline Polpa cítrica & 97,30 & 7,51 & 3,23 & 10,97 & 6,28 & 9,89 & 5,75 & 5,51 & 72,78 & 73,86 & 12,36 & 9,49 \\
\hline Sorgo & 90,82 & 12,49 & 1,56 & 10,18 & 1,88 & 8,69 & 1,62 & 1,09 & 74,68 & 76,17 & 5,13 & 1,38 \\
\hline \multicolumn{13}{|l|}{ Alimento proteico } \\
\hline Amireia & 97,87 & 153,17 & - & 2,85 & 0,47 & 1,61 & 0,33 & 0,02 & - & - & 0,08 & 0,03 \\
\hline Farelo de algodão $28 \%$ & 91,33 & 30,39 & 0,52 & 30,93 & 17,45 & 29,16 & 16,44 & 3,88 & 34,27 & 36,04 & 6,56 & 2,08 \\
\hline Farelo de algodão $38 \%$ & 90,72 & 38,35 & 0,91 & 21,68 & 10,93 & 18,95 & 10,14 & 6,21 & 32,84 & 35,57 & 5,05 & 1,41 \\
\hline Farelo de algodão $46 \%$ & 93,29 & 45,43 & 0,75 & 17,86 & 8,76 & 15,12 & 7,73 & 5,45 & 30,51 & 33,25 & 4,93 & 1,47 \\
\hline Farelo de amendoin & 93,93 & 43,63 & 9,52 & 9,89 & 6,85 & 7,98 & 6,40 & 8,84 & 28,12 & 30,03 & 2,45 & 0,65 \\
\hline Farelo de girassol & 96,74 & 24,47 & 1,24 & 26,26 & 18,03 & 21,81 & 15,64 & 5,46 & 42,57 & 47,01 & 15,92 & 7,16 \\
\hline Farelo de soja & 90,36 & 45,52 & 0,94 & 10,91 & 4,46 & 10,25 & 4,29 & 7,14 & 35,49 & 36,14 & 0,82 & 0,35 \\
\hline Feijão & 95,25 & 24,39 & 1,66 & 16,10 & 4,82 & 14,06 & 4,40 & 4,24 & 53,61 & 55,65 & 7,81 & 1,51 \\
\hline Glúten & 92,31 & 62,12 & 0,78 & 24,15 & 4,71 & 10,63 & 2,70 & 1,52 & 11,42 & 24,95 & 24,53 & 1,47 \\
\hline Grão de soja & 97,44 & 39,25 & 17,51 & 10,84 & 5,79 & 9,24 & 4,91 & 5,26 & 27,14 & 28,75 & 5,08 & 0,44 \\
\hline Levedura & 94,96 & 26,90 & 0,41 & 7,06 & 1,29 & 6,46 & 0,96 & 15,22 & 50,41 & 51,01 & 0,27 & 0,10 \\
\hline Promil & 88,54 & 24,20 & 2,59 & 21,80 & 6,49 & 20,68 & 6,23 & 5,15 & 46,27 & 47,39 & 5,22 & 1,10 \\
\hline Refinazil & 97,81 & 24,67 & 3,87 & 22,86 & 6,44 & 21,21 & 5,89 & 4,96 & 43,65 & 45,29 & 5,45 & 0,68 \\
\hline \multicolumn{13}{|l|}{ Alimento volumoso } \\
\hline Casca de cacau & 96,97 & 13,51 & 4,68 & 22,80 & 15,55 & 18,57 & 12,87 & 7,51 & 51,50 & 55,73 & 29,19 & 18,10 \\
\hline Casca de café & 90,31 & 13,39 & 0,72 & 35,86 & 24,45 & 32,10 & 22,04 & 6,71 & 43,32 & 47,08 & 27,76 & 14,42 \\
\hline Casca de soja & 97,72 & 9,56 & 1,57 & 34,26 & 24,65 & 32,19 & 24,16 & 3,58 & 51,02 & 53,09 & 21,94 & 5,26 \\
\hline Silagem de capim & 90,02 & 4,72 & 0,99 & 42,65 & 28,00 & 40,98 & 26,91 & 10,33 & 41,31 & 42,98 & 15,56 & 5,94 \\
\hline Silagem de milho & 95,18 & 6,08 & 2,90 & 28,65 & 17,59 & 26,88 & 16,23 & 8,29 & 54,09 & 55,86 & 10,95 & 5,07 \\
\hline
\end{tabular}

$1 \%$ da matéria natural; $2 \%$ da matéria seca; $3 \%$ da proteína bruta. 
Utilizaram-se quatro fêmeas da raça Nelore, fistuladas no rúmen e no duodeno e mantidas em sistema de alimentação à vontade. Os animais foram alojados em baias individuais cobertas, com piso de concreto revestido de borracha, de $3 \times 3 \mathrm{~m}$ de área, e dotadas de comedouros e bebedouros individuais. Antes do início das incubações, os animais passaram por um período de adaptação à dieta de sete dias. A ração foi constituída de silagem de milho como volumoso (75\% na base da MS total da dieta) e concentrado (25\%) à base de milho moído, farelo de algodão $38 \%$ e ureia:sulfato de amônio (9:1) (dieta total com $12,5 \%$ de PB). A alimentação foi fornecida duas vezes ao dia, cerca de $60 \%$ pela manhã, às $7 \mathrm{~h}$, e os $40 \%$ restantes às $16 \mathrm{~h}$, permitindo no máximo $5 \%$ de sobras.

Os parâmetros de degradação ruminal da MS e PB foram determinados utilizando-se sacos de náilon devidamente identificados, medindo $10 \times 20 \mathrm{~cm}$, com porosidade de 50 micrômetros, contendo amostra de $5 \mathrm{~g}$ de cada alimento, previamente moída a $2 \mathrm{~mm}$. Os tempos de incubação foram de $0,2,4,6,12,24,48$ e 72 horas; os primeiros sacos foram mantidos por 72 horas no rúmen e os outros foram colocados nos respectivos horários, de modo que todos foram retirados ao mesmo tempo. Sete sacos de cada alimento (excluindo os do tempo zero) foram incubados no rúmen de dois animais. Foram colocados no máximo 49 sacos de náilon no rúmen de cada animal. Também foram utilizados os dados da degradação da proteína do tempo de 16 horas de incubação proveniente da técnica de três estágios.

As amostras foram incubadas por intermédio da fístula ruminal, fixadas a uma corrente de aço com peso na extremidade, permitindo sua imersão no conteúdo ruminal. Decorrido o tempo de incubação, os sacos foram lavados em água corrente e levados a estufa a $65^{\circ} \mathrm{C}$ por 72 horas para quantificação da MS e do nitrogênio total dos resíduos da incubação. Os sacos referentes ao tempo zero não foram incubados no rúmen, mas foram lavados em água corrente, à semelhança dos sacos incubados.

Os perfis de degradação da MS e PB foram estimados utilizando-se o modelo assintótico de primeira ordem reparametrizado por Ørskov \& McDonald (1979), descrito pela função: $Y_{t}=A+B \times\left(1-e^{(-K d \times t)}\right)$, em que $Y_{t}=$ fração degradada no tempo t; $\mathrm{A}=$ fração solúvel; $\mathrm{B}=$ fração insolúvel potencialmente degradável; $\mathrm{Kd}=$ taxa de degradação de $\mathrm{B}$ e $\mathrm{t}$ = variável independente tempo. A fração efetivamente degradada da $\mathrm{PB}$ e da MS foi calculada pelo modelo: $\mathrm{DE}=\mathrm{A}+\mathrm{B} \times \mathrm{Kd} /(\mathrm{Kd}+\mathrm{kp})$, em que kp é a taxa de passagem do alimento pelo rúmen. Foi utilizado o proc NLIN do SAS (1997) para estimação dos parâmetro A, B e $\mathrm{kd}$, de modo que, quando $\mathrm{A}+\mathrm{B}$ somavam mais de $100 \%$, os parâmetros eram corrigidos proporcionalmente para que completassem no máximo esse valor.

Para a estimação da digestibilidade intestinal da proteína bruta, foram utilizadas a técnica do saco de náilon móvel (Hvelplund, 1985; Voigt et al., 1985) e a técnica de três estágios (Calsamiglia \& Stern, 1995).

Pela técnica do saco de náilon móvel, foram utilizados sacos de náilon de $5 \times 3 \mathrm{~cm}$ com abertura de poro de $45 \mu \mathrm{m}$. Os sacos foram devidamente identificados e levados à estufa de ventilação forçada a $65^{\circ} \mathrm{C}$, durante 24 horas, e posteriormente pesados. As amostras, moídas a $1 \mathrm{~mm}$, foram posteriormente pesadas $(0,3 \mathrm{~g}$ de amostra e dez sacos por alimento) e os sacos, selados a quente, foram colocados em sacos de filó e incubados no rúmen de um dos animais por 16 horas. Decorrido esse tempo, dois sacos de cada alimento foram lavados e secos em estufa para a quantificação da proteína degradada no rúmen, e oito foram usados para a infusão no duodeno.

Os sacos resultantes da incubação ruminal foram incubados em $400 \mathrm{~mL}$ de líquido abomasal, por 2 horas, a $39^{\circ} \mathrm{C}$ sob agitação, e depois submetidos à digestão intestinal.

Os oito sacos de náilon foram infundidos no intestino delgado, via fístula duodenal, em intervalos de cinco minutos para cada dois sacos, na proporção de dois sacos de cada alimento por animal. Foram infundidos no máximo oito sacos por animal por dia, totalizando quatro alimentos por dia e oito dias de infusão em cada animal. A partir de 2 horas após a infusão, em intervalos de 6 horas, todas as fezes dos animais foram lavadas para recuperação dos sacos, que posteriormente foram lavados em água corrente e secos em estufa de ventilação forçada a $65^{\circ} \mathrm{C}$ por 48 horas. O tempo de retenção dos sacos de náilon no intestino foi obtido pela diferença entre o horário de infusão no duodeno e o de excreção nas fezes.

As digestibilidades intestinais da MS e PB foram obtidas pela diferença entre as quantidades colocadas nos sacos de náilon antes da incubação no líquido abomasal e remanescentes nos sacos após a excreção fecal.

Pela técnica de três estágios (Calsamiglia \& Stern, 1995), a proteína degradada no rúmen (PDR) foi estimada por incubação ruminal durante 16 horas, de cerca de $5 \mathrm{~g}$ de amostra dos alimentos (moídos a $2 \mathrm{~mm}$ ), por meio de sacos de náilon. Após a incubação ruminal, os sacos foram lavados em água corrente e colocados em estufa de ventilação forçada a $65^{\circ} \mathrm{C}$ por 48 horas. Para simulação da digestão intestinal da proteína dos resíduos, primeiramente avaliou-se a concentração de nitrogênio e, com base nos valores obtidos, os resíduos com $15 \mathrm{mg}$ de nitrogênio (no máximo $0,5 \mathrm{~g}$ de amostra) foram pesados e colocados em erlenmeyers de $250 \mathrm{~mL}$. Posteriormente, foram incubados 
com $10 \mathrm{~mL}$ de solução $0,1 \mathrm{~N}$ de $\mathrm{HCl}$ contendo $1 \mathrm{~g} / \mathrm{L}$ de pepsina $(\mathrm{pH}=1,9)$, tampados com papel alumínio e colocados sob agitação durante 1 hora a $39^{\circ} \mathrm{C}$. Decorrido esse tempo, foram adicionados $0,5 \mathrm{~mL}$ de solução $1 \mathrm{~N}$ de $\mathrm{NaOH}$ para neutralização do $\mathrm{pH}$ e $13,5 \mathrm{~mL}$ de solução de pancreatina $\left(0,5 \mathrm{M}\right.$ de solução de $\left.\mathrm{KH}_{2} \mathrm{PO}_{4}, \mathrm{pH}=7,8\right)$ contendo $50 \mathrm{ppm}$ de thymol, para prevenir o crescimento microbiano, e $3 \mathrm{~g} / \mathrm{L}$ de pancreatina durante mais 24 horas. Quando verificada a evaporação do líquido de digestão, foi adicionada água destilada para evitar a secagem total do líquido.

Ao final da digestão, os resíduos foram imediatamente filtrados em papel-filtro, lavados com $200 \mathrm{~mL}$ de água destilada, digeridos em $\mathrm{H}_{2} \mathrm{SO}_{4}$ juntamente com o papelfiltro, e o nitrogênio residual estimado pelo método Kjeldahl. A digestibilidade intestinal da proteína nãodegradada no rúmen (PNDR), em porcentagem, foi calculada como a quantidade de PB digerida após a incubação com pepsina e pancreatina dividida pela quantidade de proteína incubada multiplicada por 100 .
A técnica do saco de náilon móvel foi utilizada como padrão na comparação da técnica dos três estágios, por meio de regressão linear, com hipótese de nulidade $\mathrm{H}_{0}: \beta_{0}=0$ e $\beta_{1}=1$ e hipótese alternativa $\mathrm{H}_{\mathrm{a}}$ : não $\mathrm{H}_{0}$. As análises de regressão foram realizadas utilizando-se o programa SAS (1997) com o nível de 5\% de probabilidade.

\section{Resultados e Discussão}

O farelo de trigo apresentou valores das frações A, B e kd (Tabela 2) próximos aos encontrados por Valadares Filho et al. (2006), de 47,06; 42,42; e 0,129, respectivamente. $\mathrm{O}$ farelo de babaçu foi o alimento energético que teve a menor degradação efetiva da MS (Tabela 3), em decorrência de sua alta proporção de FDA. O farelo de gérmen de milho apresentou valores de A, B e kd de 49,31; 49,49 e 0,053, inferiores aos encontrados por Zeoula et al. (2006) para a fração A $(57,59)$ e superiores aos da fração potencialmente degradável e para o $\mathrm{Kd}$, de 40,83 e 0,03 descritos por esses autores.

Tabela 2 - Fração solúvel da matéria seca (A), fração potencialmente degradável (B) e taxa de degradação da fração potencialmente degradável $(\mathrm{kd})$ de alimentos para ruminantes

\begin{tabular}{|c|c|c|c|c|}
\hline Alimento & A & $\mathrm{B}$ & $\mathrm{kd}$ & $\mathrm{DPA}^{1}$ \\
\hline \multicolumn{5}{|l|}{ Alimento energético } \\
\hline Farelo de arroz & 65,33 & 18,34 & 0,053 & 1,40 \\
\hline Farelo de babaçu & 23,57 & 65,00 & 0,030 & 4,20 \\
\hline Farelo de trigo & 57,62 & 31,65 & 0,052 & 2,83 \\
\hline Farelo de gérmen de milho & 49,31 & 49,49 & 0,053 & 2,00 \\
\hline Milho desintegrado com sabugo & 45,00 & 54,54 & 0,050 & 5,40 \\
\hline Milho desintegrado com palha e sabugo & 35,38 & 62,63 & 0,047 & 6,27 \\
\hline Milho & 45,13 & 53,91 & 0,080 & 4,48 \\
\hline Polpa cítrica & 47,34 & 52,66 & 0,084 & 5,14 \\
\hline Sorgo & 45,84 & 54,16 & 0,040 & 6,96 \\
\hline \multicolumn{5}{|l|}{ Alimento proteico } \\
\hline Amireia & 82,72 & 14,81 & 0,313 & 2,03 \\
\hline Farelo de algodão $28 \%$ de $\mathrm{PB}$ & 34,60 & 44,76 & 0,042 & 4,00 \\
\hline Farelo de algodão $38 \%$ de PB & 33,62 & 56,30 & 0,044 & 3,24 \\
\hline Farelo de algodão $46 \%$ de PB & 36,66 & 51,85 & 0,057 & 4,03 \\
\hline Farelo de amendoim & 58,02 & 36,43 & 0,131 & 2,81 \\
\hline Farelo de girassol & 32,66 & 32,21 & 0,079 & 3,35 \\
\hline Farelo de soja & 47,13 & 52,57 & 0,079 & 4,91 \\
\hline Feijão bandinha & 50,22 & 47,87 & 0,068 & 2,86 \\
\hline Glúten de milho & 16,55 & 70,64 & 0,018 & 2,02 \\
\hline Grão de soja & 15,12 & 84,99 & 0,153 & 2,23 \\
\hline Levedura & 96,09 & 2,80 & 0,210 & 0,75 \\
\hline Promil & 52,40 & 47,20 & 0,048 & 2,77 \\
\hline Refinazil & 58,06 & 41,94 & 0,041 & 1,36 \\
\hline \multicolumn{5}{|l|}{ Alimento volumoso } \\
\hline Casca de cacau & 40,67 & 37,20 & 0,032 & 3,38 \\
\hline Casca de café & 30,85 & 25,95 & 0,029 & 2,69 \\
\hline Casca de soja & 16,54 & 83,46 & 0,041 & 4,81 \\
\hline Silagem de capim-elefante & 17,87 & 45,01 & 0,032 & 1,73 \\
\hline Silagem de milho & 28,96 & 56,93 & 0,028 & 5,03 \\
\hline
\end{tabular}

\footnotetext{
1 Desvio-padrão assintótico.
} 
Tabela 3 - Degradação efetiva da matéria seca de alimentos para ruminantes em três taxas de passagem

\begin{tabular}{|c|c|c|c|}
\hline \multirow[t]{2}{*}{ Alimento } & \multicolumn{3}{|c|}{ Taxa de degradação efetiva } \\
\hline & $2 \%$ & $5 \%$ & $8 \%$ \\
\hline \multicolumn{4}{|l|}{ Alimento energético } \\
\hline Farelo de babaçu & 62,61 & 47,98 & 41,33 \\
\hline Farelo de trigo & 80,42 & 73,72 & 70,06 \\
\hline Farelo de gérmen de milho & 85,27 & 74,81 & 69,07 \\
\hline Milho desintegrado com sabugo & 84,04 & 72,37 & 66,07 \\
\hline Milho & 88,28 & 78,34 & 72,12 \\
\hline Polpa cítrica & 89,88 & 80,36 & 74,32 \\
\hline Sorgo & 81,97 & 69,93 & 63,91 \\
\hline \multicolumn{4}{|l|}{ Alimento proteico } \\
\hline Amireia & 96,63 & 95,48 & 94,51 \\
\hline Farelo de algodão $28 \%$ de $\mathrm{PB}$ & 64,91 & 55,03 & 50,00 \\
\hline Farelo de soja & 89,33 & 79,53 & 73,42 \\
\hline Feijão bandinha & 87,22 & 77,82 & 72,23 \\
\hline Glúten de milho & 49,70 & 35,01 & 29,34 \\
\hline Grão de soja & 84,14 & 68,97 & 59,26 \\
\hline Levedura & 98,65 & 98,35 & 98,12 \\
\hline Promil & 85,66 & 75,46 & 70,04 \\
\hline Refinazil & 86,27 & 76,97 & 72,29 \\
\hline \multicolumn{4}{|l|}{ Volumoso } \\
\hline Casca de cacau & 63,68 & 55,31 & 51,40 \\
\hline Casca de café & 46,20 & 40,37 & 37,75 \\
\hline Casca de soja & 72,51 & 54,00 & 44,70 \\
\hline
\end{tabular}

O milho é um dos alimentos com maior quantidade de informações na literatura. A fração A encontrada para esse alimento foi superior àquela comumente observada (Passini et al., 2004; Oliveira et al., 2003; Valadares Filho et al., 2006). Apesar de todos os trabalhos terem sido realizados utilizando-se o saco de náilon para fazer a degradação da MS, Casali (2006) mostrou que esse material tem alta porosidade, o que acarreta maiores erros de estimação da fração A.

Os valores de degradação da polpa cítrica foram próximos àqueles encontrados na literatura (Goes et al., 2004; Valadares Filho et al., 2006). Entre os alimentos energéticos, a polpa cítrica foi o que apresentou maior potencial de substituição ao milho, pois sua degradação efetiva da MS foi bem próxima à desse alimento. $\mathrm{O}$ farelo de gérmen de milho, milho desintegrado com sabugo e sorgo também se mostraram promissores.

Os parâmetros de degradação do sorgo foram muito diferentes daqueles apresentados por Valadares Filho et al. (2006) $(18,29 ; 65,19$ e $0,044 \%$, para as frações A, B e kd respectivamente), porém foram próximos àqueles encontrados para o milho, cujas características são bem semelhantes às do sorgo. O milho e a polpa cítrica são os alimentos energéticos com maior kd, portanto com menor influência da passagem sobre sua degradação, e são alimentos interessantes para serem utilizados com fontes de nitrogênio não-proteico, como a ureia. Por outro lado, a baixa taxa de degradação do farelo de babaçu limita sua utilização, principalmente em dietas para animais de maior nível de produção.

A fração A do farelo de algodão $28 \%$ foi de $34,60 \%$ e a fração B de 44,76\% (Tabela 2), próximas aos valores descritos na literatura: 23,42 e 39,08\% (Cunha et al., 1998); 23,56 e 52,09\% (Souza et al., 2000); 39,09 e 39,19\% (Silva et al., 2005) para as frações A e B, respectivamente. Para o farelo de algodão 38\%, Valadares Filho et al. (2006) citaram valores de 27,11; 45,23 e 0,0753\% para as frações A, B e Kd, respectivamente, e valores de 22,69; 49,09 e 0,0529\% para o farelo de algodão 46\%. Moreira et al. (2003), no entanto, encontraram valores de 21,33; 63,37 e 0,0419\%. Apesar da discrepância dos valores encontrados na literatura, pela degradação efetiva, os valores encontrados neste trabalho são coerentes, pois a taxa de degradação aumentou e o teor de proteína associada à parede ruminal (PIDN/PB) 
diminuiu com a redução no percentual de casca no farelo de algodão, ou seja, quando o teor de PB do farelo de algodão aumentou de $28 \%$ para $46 \%$.

$\mathrm{O}$ farelo de amendoim apresenta alta variabilidade na degradação ruminal e os coeficientes A, B e Kd (Tabela 2) foram semelhantes aos descritos na literatura, de 20,0;67,3 e 0,077 (Goes et al., 2004), 61,7; 36,6 e 0,092 (NRC, 2001), o que está relacionado à própria variabilidade desse alimento no mercado. A falta de padronização de subproduto no mercado pode influenciar significativamente os resultados de pesquisa.

Outros alimentos avaliados também tiveram suas frações A e B da matéria seca, assim como sua taxa de degradação $(\mathrm{kd})$, de acordo com valores observados na literatura, como o farelo de arroz (Valadares Filho et al., 2006; Zeoula et al., 2006), farelo de girassol (Feitosa et al., 2005; Valadares Filho et al., 2006), farelo de soja (Souza et al., 2000; Moreira et al., 2003; Oliveira et al., 2003; Cabral et al., 2005), glúten de milho (Goes et al., 2004; Valadares Filho et al., 2006) e grão de soja (Oliveira et al., 2006; Caldas Neto et al., 2003).
Tanto o promil quanto o refinazil são alimentos conhecidos com o nome de farelo de glúten de milho, mas o comportamento de ambos foi bastante semelhante e ligeiramente superior àqueles apresentados por Valadares Filho et al. (2006), de 46,12; 36,24 e 0,0385 para A, B e Kd, respectivamente.

Entre as cascas avaliadas, a degradação efetiva encontrada foi bastante baixa, principalmente para a casca de café, e a casca de soja foi aquela que se mostrou mais promissora. Os valores encontrados para esses subprodutos foram bastante similares aos descritos por Zeoula et al. (2006), de 16,84; 69,53 e 0,03 para as frações A, B e Kd, respectivamente, e Oliveira et al. (2006), 15,21; 79,36, e 0,038. Valadares Filho et al. (2006) citaram valores de 17,88; 74,59 e 0,031 para essas mesmas frações da casca de soja.

Nas silagens, observou-se variação muito grande em relação aos resultados encontrados na literatura. A silagem de capim-elefante apresenta valores de 62,$67 ; 46,75$ e 0,026, segundo Rêgo et al. (2006a); de 57,46; 40,27 e 0,042, segundo Rêgo et al. (2006b), de 16,68; 48,22 e 0,0325,

Tabela 4 - Fração solúvel da proteína bruta (A), fração potencialmente degradável (B) e taxa de degradação da fração potencialmente degradável $(\mathrm{Kd})$ de alimentos para ruminantes

\begin{tabular}{|c|c|c|c|c|}
\hline Alimento & A & $\mathrm{B}$ & $\mathrm{Kd}$ & $\mathrm{DPA}^{1}$ \\
\hline \multicolumn{5}{|l|}{ Alimento energético } \\
\hline Farelo de arroz & 73,27 & 22,45 & 0,061 & 3,17 \\
\hline Farelo de babaçu & 29,87 & 70,13 & 0,026 & 5,12 \\
\hline Farelo de trigo & 56,08 & 39,10 & 0,182 & 2,25 \\
\hline Farelo de gérmen de milho & 55,27 & 44,73 & 0,036 & 1,86 \\
\hline Milho desintegrado com sabugo & 39,81 & 60,19 & 0,035 & 6,70 \\
\hline Milho desintegrado com palha e sabugo & 40,46 & 59,54 & 0,049 & 6,23 \\
\hline Milho & 42,79 & 57,21 & 0,038 & 5,47 \\
\hline Polpa cítrica & 58,49 & 41,28 & 0,077 & 4,64 \\
\hline Sorgo & 41,21 & 58,79 & 0,039 & 7,87 \\
\hline \multicolumn{5}{|l|}{ Alimento proteico } \\
\hline Amireia & 99,06 & 0,88 & 0,057 & 0,12 \\
\hline Farelo de algodão $28 \%$ de $\mathrm{PB}$ & 57,96 & 40,57 & 0,068 & 4,33 \\
\hline Farelo de algodão $38 \%$ de $\mathrm{PB}$ & 34,01 & 63,54 & 0,064 & 5,27 \\
\hline Farelo de algodão $46 \%$ de $\mathrm{PB}$ & 39,19 & 58,98 & 0,086 & 6,13 \\
\hline Farelo de amendoim & 67,30 & 32,71 & 0,120 & 4,02 \\
\hline Farelo de girassol & 39,52 & 36,62 & 0,104 & 3,61 \\
\hline Farelo de soja & 33,85 & 66,15 & 0,101 & 8,72 \\
\hline Feijão bandinha & 54,57 & 45,22 & 0,091 & 2,87 \\
\hline Glúten de milho & 10,21 & 46,93 & 0,066 & 7,47 \\
\hline Grão de soja & 32,31 & 67,69 & 0,118 & 5,34 \\
\hline Levedura & 98,56 & 1,20 & 0,073 & 0,34 \\
\hline Promil & 76,96 & 22,00 & 0,074 & 2,16 \\
\hline Refinazil & 67,15 & 29,06 & 0,077 & 2,88 \\
\hline \multicolumn{5}{|l|}{ Alimento volumoso } \\
\hline Casca de cacau & 37,20 & 36,40 & 0,041 & 3,91 \\
\hline Casca de café & 52,78 & 22,38 & 0,026 & 7,00 \\
\hline Casca de soja & 34,27 & 65,73 & 0,023 & 4,68 \\
\hline Silagem de capim-elefante & 48,83 & 12,86 & 0,068 & 3,79 \\
\hline Silagem de milho & 59,10 & 22,52 & 0,030 & 2,60 \\
\hline
\end{tabular}

1 Desvio-padrão assintótico. 
segundo Cabral et al. (2005); e de 4,22; 60,49 e 0,0225, segundo Valadares Filho et al. (2006), para as frações A, B e $\mathrm{Kd}$, respectivamente, enquanto para a silagem de milho são citados valores de 26,80; 52,50 e 0,04 (Caldas Neto et al., 2003); 26,73; 57,15 e 0,0390 (Cabral et al., 2005); e 22,70; 52,28 e 0,0268 (Valadares Filho et al., 2006).

Resultados diferentes da literatura foram observados neste trabalho para a degradação ruminal da PB do farelo de arroz (Tabela 4). Valadares Filho et al. (2006) encontraram 37,$07 ; 46,65$ e 0,056 e, no NRC (2001), são descritos valores de 32,06; 49,00 e 0,05 para A, B e kd, respectivamente, porém Zeoula et al. (2006) encontraram coeficientes de 58,36; 24,61 e 0,05 para as frações A, B e Kd da PB. O farelo de arroz é um alimento com composição muito variável, principalmente em virtude dos teores de proteína e extrato etéreo, o que pode ter contribuído para essa variabilidade nos resultados.

Em geral os valores de A, B e Kd do milho variam muito, mas os valores (Tabela 4) foram, em média, maiores para a fração solúvel e menores para a fração potencialmente degradável (Oliveira et al., 2003; Valadares Filho et al., 2006; Zeoula et al., 2006). As respostas encontradas neste trabalho para a polpa cítrica seguiram o mesmo comportamento do milho e possuem a mesma discrepância em relação aos dados da literatura (NRC, 2001; Goes et al., 2004; Valadares Filho et al., 2006).

No sorgo os valores de A foram maiores e os de B menores que aqueles descritos por Valadares Filho et al. (2006) e pelo NRC (2001), mas esse comportamento seguiu a mesma tendência do milho. $\mathrm{O}$ farelo de trigo, no entanto, apresentou comportamento bastante semelhante ao descrito por Valadares Filho et al. (2006), mas diferente do NRC (2001) e de Goes et al. (2004). Os valores encontrados para o farelo de gérmen de milho também se assemelharam aos descritos por Zeoula et al. (2006).

Entre os alimentos energéticos, a polpa cítrica, o farelo de arroz e o farelo de trigo apresentaram as maiores degradações efetivas da PB (Tabela 5) e são boas opções de fonte de PDR, apesar de não serem utilizados como fonte de proteína. $\mathrm{O}$ farelo de babaçu foi o alimento de menor degradação efetiva da PB, uma vez que grande quantidade da proteína desse alimento está associada à parede celular; sua relação PIDN/PB foi de 35,10, a maior entre todos os alimentos estudados.

Tabela 5 - Degradação efetiva da proteína bruta de alimentos para ruminantes em três taxas de passagem

\begin{tabular}{|c|c|c|c|}
\hline & \multicolumn{3}{|c|}{ Taxa de degradação efetiva } \\
\hline & $2 \%$ & $5 \%$ & $8 \%$ \\
\hline \multicolumn{4}{|l|}{ Alimento energético } \\
\hline Farelo de arroz & 90,21 & 85,65 & 83,03 \\
\hline Farelo de babaaçu & 69,61 & 53,96 & 47,15 \\
\hline Farelo de trigo & 91,31 & 86,76 & 83,25 \\
\hline Farelo de gérmen de milho & 84,00 & 73,97 & 69,13 \\
\hline Milho desintegrado com sabugo & 78,03 & 64,51 & 58,06 \\
\hline Milho desintegrado com palha e sabugo & 82,65 & 69,82 & 62,97 \\
\hline Milho & 80,13 & 67,34 & 61,07 \\
\hline Polpa cítrica & 91,22 & 83,46 & 78,67 \\
\hline Sorgo & 80,01 & 66,90 & 60,41 \\
\hline \multicolumn{4}{|l|}{ Alimento proteico } \\
\hline Amireia & 99,71 & 99,53 & 99,43 \\
\hline Farelo de algodão $28 \%$ de $\mathrm{PB}$ & 89,34 & 81,37 & 76,63 \\
\hline Farelo de algodão $38 \%$ de $\mathrm{PB}$ & 82,39 & 69,64 & 62,21 \\
\hline Farelo de algodão $46 \%$ de $\mathrm{PB}$ & 87,02 & 76,45 & 69,71 \\
\hline Farelo de amendoim & 95,32 & 90,37 & 86,91 \\
\hline Farelo de girassol & 70,24 & 64,26 & 60,23 \\
\hline Farelo de soja & 89,03 & 78,03 & 70,70 \\
\hline Feijão bandinha & 91,66 & 83,78 & 78,67 \\
\hline Glúten de milho & 46,17 & 36,84 & 31,35 \\
\hline Grão de soja & 87,97 & 76,25 & 68,61 \\
\hline Levedura & 99,50 & 99,27 & 99,13 \\
\hline Promil & 94,27 & 90,07 & 87,52 \\
\hline Refinazil & 90,20 & 84,74 & 81,37 \\
\hline \multicolumn{4}{|l|}{ Alimento volumoso } \\
\hline Casca de cacau & 61,62 & 53,55 & 49,49 \\
\hline Casca de café & 65,39 & 60,40 & 58,24 \\
\hline Casca de soja & 69,42 & 54,97 & 48,94 \\
\hline Silagem de capim-elefante & 58,77 & 56,25 & 54,75 \\
\hline Silagem de milho & 72,69 & 67,62 & 65,30 \\
\hline
\end{tabular}


Os coeficientes de degradação da PB (Tabela 4) do farelo de algodão $28 \%$ encontrados na literatura são bastante discrepantes. Cunha et al. (1998) encontraram valores de 21,31; 72,18 e 0,0231 para as frações A, B e Kd da proteína bruta, enquanto Silva et al. (2005) citaram valores de 10,52; 85,26 e 0,1393. Valadares Filho et al. (2006) descreveram estimativas de 22,$70 ; 68,69$ e 0,1143 para o farelo de algodão $38 \%$ e de 29,$60 ; 64,55$ e 0,0639 para o farelo de algodão 46\%. Moreira et al. (2003) relataram para o farelo de algodão $46 \%$ valores de 32,25; 71,35 e 0,0435 para A, B e Kd. Neste trabalho, apenas a taxa de degradação da fração insolúvel difere da literatura. A relação PIDN/PB aumentou de acordo com o teor de casca no farelo de algodão, diminuindo a degradação efetiva da proteína bruta desses alimentos (Tabela 5).

Para o farelo de amendoim, Goes et al.(2004) citaram valores discrepantes daqueles apresentados neste trabalho, porém o NRC (2001) apresentou valores muito próximos valores de degradação ruminal da proteína bruta. Observou-se alta proporção de $\mathrm{PIDN} / \mathrm{PB}$ para o farelo de girassol, o que pode explicar a baixa degradação efetiva da PB deste alimento em comparação à maioria daqueles alimentos proteicos avaliados. Os parâmetros de degradação foram inferiores aos reportados por Valadares Filho et al. (2006) e pelo NRC (2001).

O farelo de soja também apresentou valores de degradação ruminal da proteína bruta próximos ao encontrado na literatura (NRC, 2001; Oliveira et al., 2003; Goes et al., 2004; Valadares Filho et al., 2006).

Para o glúten de milho, os coeficientes A, B e Kd da literatura variam muito e são de 10,55; 71,95 e 0,0537 (Valadares Filho et al., 2006); de 3,9; 90,9 e 0,052 (NRC, 2001); de 0,2; 94,9 e 0,005 (Goes et al., 2004). Moreira et al. (2003) não encontraram um padrão de fermentação para o glúten de milho condizente com o modelo de Ørskov \& McDonald (1979).

Os coeficientes de degradação ruminal da proteína bruta encontrados para o grão de soja estão de acordo com os dados da literatura (NRC, 2001; Caldas Neto et al., 2003; Oliveira et al., 2006). O promil e o refinazil, assim como para a degradação da matéria seca, apresentaram comportamento semelhante e ambos próximos aos valores citados por Valadares Filho et al. (2006), mas diferentes daqueles

Tabela 6 - Digestão intestinal da proteína não-degradada no rúmen de alimentos para ruminantes pela técnica do saco de náilon móvel e pela técnica dos três estágios

Técnica do saco de náilon móvel

Técnica dos três estágios

\begin{tabular}{|c|c|c|}
\hline \multicolumn{3}{|l|}{ Alimento energético } \\
\hline Farelo de arroz & $12,87 \pm 0,81$ & 26,74 \\
\hline Farelo de babaçu & $70,65 \pm 1,04$ & 63,00 \\
\hline Farelo de trigo & $29,56 \pm 3,00$ & 33,33 \\
\hline Farelo de gérmen de milho & $81,30 \pm 3,06$ & 68,47 \\
\hline Milho desintegrado com sabugo & $76,06 \pm 1,26$ & 73,50 \\
\hline Milho desintegrado com palha e sabugo & $82,70 \pm 1,38$ & 71,76 \\
\hline Milho & $85,58 \pm 1,28$ & 84,58 \\
\hline Polpa cítrica & $31,82 \pm 0,93$ & 27,71 \\
\hline Sorgo & $76,90 \pm 1,55$ & 84,74 \\
\hline \multicolumn{3}{|l|}{ Alimento proteico } \\
\hline Amireia & - & - \\
\hline Farelo de algodão $28 \%$ de $\mathrm{PB}$ & $54,46 \pm 0,93$ & 52,01 \\
\hline Farelo de algodão $38 \%$ de $\mathrm{PB}$ & $75,91 \pm 1,45$ & 72,71 \\
\hline Farelo de algodão $46 \%$ de $\mathrm{PB}$ & $84,93 \pm 1,39$ & 67,10 \\
\hline Farelo de amendoim & $27,81 \pm 2,35$ & 48,07 \\
\hline Farelo de girassol & $45,55 \pm 0,48$ & 31,54 \\
\hline Farelo de soja & $93,95 \pm 0,38$ & 91,86 \\
\hline Feijão bandinha & $19,39 \pm 2,88$ & 21,79 \\
\hline Glúten de milho & $82,98 \pm 3,54$ & 85,82 \\
\hline Grão de soja & $32,36 \pm 18,26$ & 39,97 \\
\hline Levedura & 87,51 & - \\
\hline Promil & $63,16 \pm 1,20$ & 45,47 \\
\hline Refinazil & $54,73 \pm 3,78$ & 54,73 \\
\hline \multicolumn{3}{|l|}{ Alimento volumoso } \\
\hline Casca de cacau & $4,25 \pm 1,62$ & 8,93 \\
\hline Casca de café & $7,84 \pm 1,46$ & 6,48 \\
\hline Casca de soja & $32,06 \pm 1,18$ & 40,38 \\
\hline Silagem de capim-elefante & $36,26 \pm 2,71$ & - \\
\hline Silagem de milho & $25,74 \pm 3,30$ & - \\
\hline
\end{tabular}


mostrados no NRC (2001) (48,0; 43,2 e 0,077, para A, B e kd, respectivamente).

Entre os alimentos proteicos, o glúten de milho foi o que apresentou menor degradação efetiva da PB $(36,84$ a uma taxa da passagem de $5 \%$ ), portanto foi aquele com maior potencial para uso como fonte de PNDR. Para fontes de PDR, à exceção da amireia e levedura, que possuem degradação efetiva próxima de $100 \%$, o farelo de amendoim, o feijão-bandinha e o promil foram os mais promissores.

A casca de café apresentou valores semelhantes àqueles citados por Valadares Filho et al. (2006), de 52,04; 28,23 e 0,03, para A, B e Kd, respectivamente. Para a casca de soja, os valores foram semelhantes (Tabela 4) aos descritos por Zeoula et al. (2006) e Oliveira et al. (2006).

O comportamento da silagem de capim-elefante foi bastante próximo ao encontrado por Cabral et al. (2005), mas diferente daquele apresentado por Valadares Filho et al. (2006). Para a silagem de milho, os valores obtidos neste trabalho também estão condizentes com aqueles encontrados na literatura (NRC, 2001; Caldas Neto et al., 2003; Valadares Filho et al., 2006). A variação nos valores de degradação da proteína bruta em alimentos volumosos tende a ser maior, em decorrência da maior contaminação bacteriana no material durante sua incubação no rúmen.

Durante a realização da técnica dos sacos de náilon móveis, houve uma recuperação de $97,68 \%$ dos sacos incubados e, após a incubação ruminal, não houve sobra de amostra suficiente para determinação da digestão intestinal da proteína não-degradada no rúmen da amireia, o que indica que praticamente $100 \%$ da proteína deste alimento está na forma de proteína degradada no rúmen, como ocorre para a levedura.

As digestibilidades intestinais encontradas por Mesgaran \& Stern (2005) para o milho, farelo de trigo e farelo de soja foram inferiores àquelas encontradas neste experimento (Tabela 6). Beran et al. (2005), estudando a técnica dos três estágios, encontraram valores semelhantes de digestibilidade intestinal para o farelo de girassol, mas valores superiores para a digestibilidade total da PB (Tabela 7).

Tabela 7 - Digestibilidade total da proteína bruta em três taxas de passagens (2, 5 e 8\%) e sua divisão em PDR e PNDR de alimentos para ruminantes

\begin{tabular}{|c|c|c|c|c|c|c|c|c|c|}
\hline \multirow[t]{2}{*}{ Alimento } & DTPB & $\mathrm{PDR}^{1}$ & $\mathrm{PNDR}^{1,2}$ & DTPB & $\mathrm{PDR}^{1}$ & PNDR $^{1,2}$ & DTPB & $\mathrm{PDR}^{1}$ & PNDR $^{1,2}$ \\
\hline & \multicolumn{3}{|c|}{$2 \%$} & \multicolumn{3}{|c|}{$5 \%$} & \multicolumn{3}{|c|}{$8 \%$} \\
\hline \multicolumn{10}{|l|}{ Alimento energético } \\
\hline Farelo de babaçu & 91,08 & 76,43 & 23,57 & 86,49 & 62,39 & 37,61 & 84,49 & 55,81 & 44,19 \\
\hline Farelo de trigo & 93,88 & 97,26 & 2,74 & 90,67 & 95,68 & 4,32 & 88,20 & 94,39 & 5,61 \\
\hline Farelo de gérmen de milho & 97,01 & 86,59 & 13,41 & 95,13 & 77,76 & 22,24 & 94,23 & 73,37 & 26,63 \\
\hline Milho desintegrado com sabugo & 94,74 & 82,37 & 17,63 & 91,50 & 70,50 & 29,50 & 89,96 & 64,54 & 35,46 \\
\hline Polpa cítrica & 94,01 & 97,03 & 2,97 & 88,72 & 94,07 & 5,93 & 85,46 & 92,06 & 7,94 \\
\hline Sorgo & 95,38 & 83,88 & 16,12 & 92,35 & 72,44 & 27,56 & 90,86 & 66,49 & 33,51 \\
\hline \multicolumn{10}{|l|}{ Alimento proteico } \\
\hline Amireia & 99,94 & 100,0 & - & 99,94 & 100,0 & - & 99,94 & 100,0 & - \\
\hline Farelo de algodão $28 \%$ de $\mathrm{PB}$ & 95,14 & 93,89 & 6,11 & 91,52 & 88,92 & 11,08 & 89,36 & 85,76 & 14,24 \\
\hline Farelo de soja & 99,34 & 89,62 & 10,38 & 98,67 & 79,08 & 20,92 & 98,23 & 71,97 & 28,03 \\
\hline Feijão bandinha & 93,27 & 98,27 & 1,73 & 86,93 & 96,38 & 3,62 & 82,80 & 95,00 & 5,00 \\
\hline Glúten de milho & 90,84 & 50,83 & 49,17 & 89,25 & 41,28 & 58,72 & 88,31 & 35,50 & 64,50 \\
\hline Grão de soja & 95,52 & 97,76 & 2,24 & 88,29 & 93,65 & 6,35 & 83,24 & 90,37 & 9,63 \\
\hline Levedura & 99,94 & 99,56 & 0,44 & 99,91 & 99,36 & 0,64 & 99,89 & 99,24 & 0,76 \\
\hline Promil & 97,89 & 96,30 & 3,70 & 96,34 & 93,49 & 6,51 & 95,40 & 91,73 & 8,27 \\
\hline Refinazil & 95,56 & 94,38 & 5,62 & 93,09 & 91,03 & 8,97 & 91,57 & 88,86 & 11,14 \\
\hline \multicolumn{10}{|l|}{ Alimento volumoso } \\
\hline Casca de cacau & 63,25 & 97,42 & 2,58 & 55,52 & 96,44 & 3,56 & 51,64 & 95,84 & 4,16 \\
\hline Casca de café & 68,10 & 96,01 & 3,99 & 63,50 & 95,11 & 4,89 & 61,51 & 94,68 & 5,32 \\
\hline Casca de soja & 79,23 & 87,62 & 12,38 & 69,41 & 79,20 & 20,80 & 65,31 & 74,93 & 25,07 \\
\hline
\end{tabular}

\footnotetext{
${ }^{1}$ Porcentagem da proteína total digestível.
}

2 Obtida pela técnica do saco de náilon móvel. 
O farelo de girassol estudado nesse experimento possuía $5 \%$ a mais de PB que o deste trabalho. Para o farelo de algodão $38 \%$ e o farelo de soja, os valores de digestibilidade intestinal foram inferiores, mas as digestibilidade totais da PB foram semelhantes. Calsamiglia \& Stern (1995) também encontraram valores semelhantes para a digestibilidade total da PB do farelo de soja.

Praticamente todos os alimentos estudados possuem digestibilidade total da proteína maior ou próxima de $90 \%$ (Tabela 7), com exceção das cascas e das silagens. Outros autores também encontraram comportamento semelhante nos estudos de vários alimentos (Rodriguez et al., 2003; Beran et al, 2007). Entre os alimentos estudados, o glúten de milho destacou-se por conter grande parte de proteína na forma de PNDR, portanto, uma importante fonte para animais de maior exigência em PNDR.

Os dados obtidos na técnica dos três estágios foram comparados àqueles encontrados pela técnica do saco de náilon móvel e, quando realizado o teste estatístico para a hipótese conjunta $\mathrm{H}_{0}: \beta_{0}=0$ e $\beta_{1}=1$, observou-se diferença significativa $(\mathrm{P}<0,05)$ entre os métodos estudados. A técnica dos três estágios foi desenvolvida com alimentos proteicos, portanto mais estudos como esse são necessários para melhor avaliação da técnica para ser utilizada em alimentos energéticos e resíduos da agroindústria. Pelo teste estatístico, para a mesma hipótese de nulidade citada anteriormente, apenas para os alimentos proteicos utilizados no experimento (Figura 1), observou-se valor P de 0,2552; o que evidencia que para alimentos proteicos a técnica dos três estágios estima com confiança os valores de digestão intestinal da proteína bruta.

Com isso, foi elaborada uma equação para se estimar a digestibilidade intestinal da proteína bruta utilizando os dados obtidos pela técnica dos três estágios para alimentos não-proteicos (Figura 2).

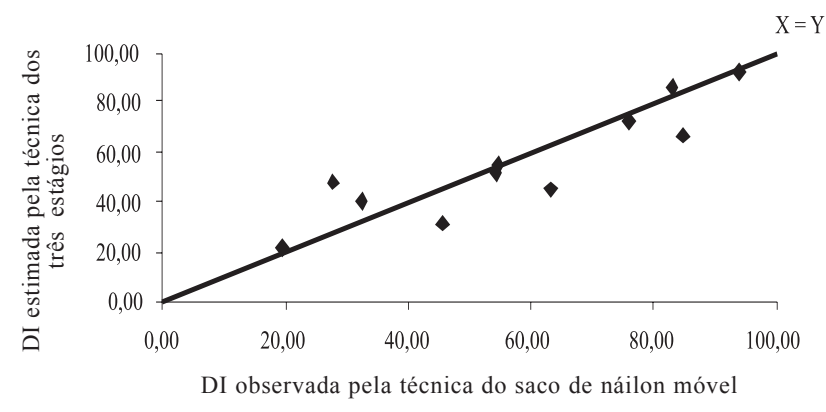

Figura 1 - Digestibilidade intestinal dos alimentos proteicos pela técnica do saco de náilon móvel em comparação à técnica dos três estágios.

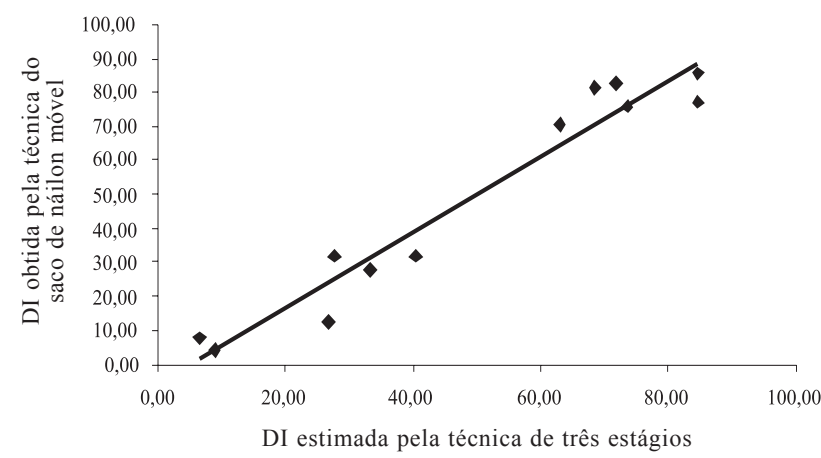

Figura 2 - Digestibilidade intestinal observada pela técnica do saco de náilon móvel em comparação à técnica dos três estágios.

A equação obtida foi: $\operatorname{DIPB}(\%)=-5,1906+1,1053 \times X$, $\mathrm{r}^{2}=0,94(\mathrm{P}<0,001)$; em que $X$ é a digestibilidade intestinal da proteína bruta obtida pela técnica dos três estágios.

\section{Conclusões}

A maioria dos alimentos estudados possui digestibilidade total da proteína bruta maior ou próxima de $90 \%$, com exceção das cascas de soja, de café e de cacau e das silagens de milho e de capim-elefante. A técnica de três estágios estima corretamente a digestibilidade intestinal dos alimentos proteicos, no entanto é recomendável utilizar a equação DIPB $(\%)=-5,1906+1,1053 \times \mathrm{X}$, para corrigir a digestibilidade de alimentos não-proteicos obtida pela técnica dos três estágios.

\section{Literatura Citada}

BERAN, F.H.B.; SILVA, L.D.F.; RIBEIRO, E.L.A. et al. Avaliação da digestibilidade de nutrientes, em bovinos, de alguns alimentos concentrados pela técnica dos três estágios. Revista Brasileira de Zootecnia, v.36, n.1, p.130-137, 2007.

CABRAL, L.S.; VALADARES FILHO, S.C.; ZERVOUDAKIS, J.T. et al. Degradabilidade in situ da matéria seca, da proteína bruta e da fibra de alguns alimentos. Pesquisa Agropecuária Brasileira, v.40, n.8, p.777-781. 2005.

CALDAS NETO, S.F.; ZEOULA, L.M.; PRADO, I.N. et al. Degradabilidade ruminal da matéria seca e proteína bruta de alguns alimentos em novilhos de corte. In: REUNIÃO DA SOCIEDADE BRASILEIRA DE ZOOTECNIA, 40., 2003, Santa Maria. Anais... Santa Maria, Sociedade Brasileira de Zootecnia, 2003. (CD-ROM).

CALSAMIGLIA, S.; STERN, M.D. A three-steep in vitro procedure for estimating intestinal digestion of protein in ruminants. Journal of Animal Science, v.73, p.1459-1465, 1995.

CASALI, A.O.; DETMANN, E.; VALADARES FILHO, S.C. et al. Estimação de teores de componentes fibrosos em alimentos para ruminantes em sacos de diferentes tecidos. Revista Brasileira de Zootecnia, v.38, n.1, p.130-138, 2009. 
CUNHA, J.A.; MELOTTI, L.; LUCCI, C. S. Degradabilidade no rúmen da matéria seca e da proteína do caroço integral e do farelo de algodão (Gossypium hirsutum L.) pela técnica dos sacos de náilon in situ com bovinos. Arquivo Brasileiro de Medicina Veterinária e Zootecnia, v.35, n.2, p.96-100, 1998.

FEITOSA, J.V.; MALHEIROS, E.B.; EZEQUIEL, J.M.B. et al. Modelos de regressão usados no estudo da curva de degradação do farelo de girassol como componente de dietas com diferentes relações volumoso:concentrado. In: REUNIÃO ANUAL DA SOCIEDADE BRASILEIRA DE ZOOTECNIA, 42., 2005. Goiânia. Anais... Goiânia: Sociedade Brasileira de Zootecnia, 2005. (CD-ROM).

FERREIRA, R.N.; ORSINE, G.F.; OLIVEIRA, E.R. et al. Valor nutricional e degradabilidade ruminal da semente e do farelo de girassol. In: CONGRESSO INTERNACIONAL DE ZOOTECNIA, 6., 2004, Brasília. Anais... Brasília: Associação Brasileira de Zootecnistas, 2004. (CD-ROM).

GOES R.H.T.B.; MANCIO, A.B.; VALADARES FILHO, S.C. et al. Degradação ruminal da matéria seca e da proteína bruta, de alimentos concentrados utilizados como suplementos para novilhos. Ciência Agrotécnica, v.28, n.1, p.167-173, 2004.

HVELPLUND, T.; WEISBJERG, M. R. In situ techniques for the estimation of protein degradability and post rumen availability. In: GIVENS, D.J.; OWENS, E.; OMED, H.M. et al. (Eds.) Forage evaluation in ruminant nutrition. London: $\mathrm{CAB}$ International, 2000, p.233-257.

HVELPLUND, T. Digestibility of rumen microbial protein and undegraded dietary protein estimated in the small intestine of sheep or by in saco procedure. Acta Agricultura Scandinavica, v.25, p.132-144, 1985 (suppl.).

MADSEN, J.; HVELPLUND, T.; WEISBJERG, M. R. et al. The Aat/ PBV protein evaluation system for ruminants: a revision. Norwegian Journal of Agricultural Science, v.19, p.1-37, 1995.

MESGARAN, M.D.; STERN, M.D. Ruminal and post-ruminal disappearance of various feeds originating from Iranian plan varieties determined by the in situ mobile bag technique and alternative methods. Animal Feed Science and Technology, v.118, p.31-46, 2005

MOREIRA, J.F.C.; RODRIGUEZ, N.M.; FERNANDES, P.C.C. et al. Concentrados proteicos para bovinos: 1. Digestibilidade in situ da matéria seca e da proteína bruta. Arquivo Brasileiro de Medicina Veterinária e Zootecnia, v.55, n.3, p.315-323, 2003.

NATIONAL RESEARCH COUNCIL - NRC. Nutrient requirements of dairy cattle. 7.ed. Washinton, D.C.: National Academic Press, 2001. 381p.

OLIVEIRA, M.V.M.; VARGAS JUNIOR, F.M.; SANCHEZ, L.M.B. et al. Degradabilidade ruminal e digestibilidade intestinal de alimentos por intermédio da técnica in situ associada à do saco de náilon móvel. Revista Brasileira de Zootecnia, v.32, n.6, p.2023-2031, 2003 (supl.2.).

OLIVEIRA, L.G.; MELO, M.A.F.; ORSINE, G.F. et al. Composição química e degradação ruminal da soja grão e seus resíduos. In: REUNIÃO DA SOCIEDADE BRASILEIRA DE ZOOTECNIA, 43., 2006, João Pessoa. Anais... João Pessoa: Sociedade Brasileira de Zootecnia, 2006. (CD-ROM).

ØRSKOV, E.R.; McDONALD, I. The estimation of protein degradability in the rumen from incubation measurements weighted according to rate of passage. Journal of Agricultural Science, v.92, p.499-503, 1979.
PASSINI, R.; BORGATTI, L.M.O; FERREIRA, F.A. et al. Degradabilidade no rúmen bovino de grãos de milho processados de diferentes formas. Pesquisa Agropecuária Brasileira, v.39, n.3, p.271-276, 2004.

RÊGO, A.C.; GOMES, F.H.T.; CÂNDIDO, M.J.D. et al. Degradabilidade "in situ" da material seca e da fibra em detergente neutro de silagens de capim elefantes contendo níveis crescentes de adição do subproduto do caju. In: REUNIÃO DA SOCIEDADE BRASILEIRA DE ZOOTECNIA, 43., 2006, João Pessoa. Anais... João Pessoa: Sociedade Brasileira de Zootecnia, 2006a. (CD-ROM)

RÊGO, A.C.; GOMES, F.H.T.; CÂNDIDO, M.J.D et al. Degradabilidade "in situ" da matéria seca de silagens de capim elefante contendo níveis crescentes de adição do subproduto do grão de urucum. In: REUNIÃO DA SOCIEDADE BRASILEIRA DE ZOOTECNIA, 43., 2006., João Pessoa. Anais... João Pessoa: Sociedade Brasileira de Zootecnia, 2006b. (CD-ROM).

RODRIGUEZ, N.M.; MOREIRA, J.F.C.; FERNANDES, P.C.C. et al Concentrados proteicos para bovinos. 2. digestão pós-ruminal da matéria seca e da proteína. Arquivo Brasileiro de Medicina Veterinária e Zootecnia, v.55, n.3, p.324-333, 2003.

SILVA, L.D.F.; CASTRO, V.S.; MORI, R.M. et al. Degradabilidade in situ de silagem de cana-de-açúcar (Saccharum spp), farelo de algodão e torta de girassol em bovinos. In: REUNIÃO ANUAL DA SOCIEDADE BRASILEIRA DE ZOOTECNIA, 42., 2005. Goiânia. Anais... Goiânia: Sociedade Brasileira de Zootecnia, 2005. (CD-ROM).

SOUZA, J.R.T.; CAMARÃO, A.P.; RÊGO, L.C. [2000]. Degradabilidade ruminal da matéria seca e proteína bruta de subprodutos da agroindústria, da pesca e de abatedouros em caprinos. Brazilian Journal of Veterinary Science, v.37, n.2, 2000. Disponível em: <http://www.scielo.br/scielo.php?script= sci_arttex\&pid=S1413-9596200000015\&1ng=en\&nrm=iso $>$. Acesso em: 17/6/2007. doi: 10.1590/S1413-9596200000015.

STATISTICAL ANALYSIS SYSTEM - SAS. Institute SAS/STAT software: changes and enhancements through release 6.12 . Cary: SAS Institute, 1997. 1167p.

VALADARES FILHO, S.C.; MAGALHÃES, K.A.; ROCHA JR., V.R. et al. Tabelas brasileiras de composição de alimentos para bovinos. 2.ed. Viçosa, MG: Universidade Federal de Viçosa, Departamento de Zootecnia, 2006. 329p

VOIGT, J.; PIATKOWSKI, B.; ENGELMANN, H. et al. Measurement of the postruminal digestibility of crude protein by the bag technique in cows. Archiv für Tierernährung, v.35, p.555-562, 1985.

ZEOULA, L.M.; GERON, L.J.V.; PRADO, I.N. et al. Degradabilidade "in situ" da material seca (ms) e proteína bruta (pb) do resíduo úmido de cervejaria, silagem do resíduo úmido de cervejaria e farelo de soja. In: REUNIÃO ANUAL DA SOCIEDADE BRASILEIRA DE ZOOTECNIA, 42., 2005. Goiânia. Anais... Goiânia: Sociedade Brasileira de Zootecnia, 2005. (CD-ROM).

ZEOULA, L.M.; KAZAMA, R.; PRADO, I.N. et al. Cascas de algodão e de soja e farelos de gérmen de milho ou de arroz na alimentação de novilhas: degradabilidade ruminal, digestibilidade aparente e desempenho. In: REUNIÃO DA SOCIEDADE BRASILEIRA DE ZOOTECNIA, 43., 2006, João Pessoa. Anais... João Pessoa: Sociedade Brasileira de Zootecnia, 2006. (CD-ROM). 